\title{
Retraction Note to: Dental Care of Oral Cancer Patients
}

\author{
Philip Williams and Trupti C. Kolur
}

\section{Retraction Note to: \\ Chapter 2 In: M. A. Kuriakose (ed.), \\ Contemporary Oral Oncology, https://doi.org/10.1007/978-3-319-43857-3_2}

This chapter [2] has been retracted by the publisher. The chapter contains sections that substantially overlap with the following articles [2, 3]. All authors agree to the retraction.

1. Williams P., Kolur T.C. (2017) Dental Care of Oral Cancer Patients. In: Kuriakose M. (eds) Contemporary Oral Oncology. Springer, Cham

2. Pretherapy dental decisions in patients with head and neck cancer: A proposed model for dental decision support, Hubert H Bruins DMD, Ron Koole DMD, MD, PhD, Daniel E Jolly DDS, Oral Surgery, Oral Medicine, Oral Pathology, Oral Radiology, and Endodontology, Volume 86, Issue 3, September 1998, Pages 256-267, https://doi.org/10.1016/S1079-2104(98)90169-X

3. Andrews, N. and Griffiths, C. (2001), Dental Complications of Head and Neck Radiotherapy: Part 2. Australian Dental Journal. 2001;46:174-182. https://doi. org/10.1111/j.1834-7819.2001.tb00278.x 